\title{
Resenha de Nathalie Quintane. Les années 10
}

Rewie of Nathalie Quintane, Les annés 10

Larissa Drigo Agostinho

Doutora pela Universidade de Paris IV-Sorbonne, Paris, França

Resenha de QUINTANE, Nathalie. Les années 10. Paris: La Fabrique, 2014.

Qual a relação entre a literatura e a teoria literária? Com o fim do estruturalismo, a teoria ocupa um lugar cada vez mais marginal no interior do pensamento francês, seguindo a tradição ou (seria maldição?) aberta pelo próprio estruturalismo, que ocupava um lugar muito pequeno no interior da vida acadêmica francesa. (Barthes, por exemplo, durante grande parte da sua carreira não teve um cargo de professor universitário.) Com a constituição do grupo Questions théoriques, ocupando o lugar deixado pelo Tel quel a teoria passou a ocupar um lugar não apenas no interior da vida universitária, mesmo que extremamente restrito, mas, sobretudo, no interior da literatura. Um dos maiores feitos de autores pertencentes a este grupo foi justamente colocar em questão a diferença entre "escritos" ou gêneros muito distintos como a teoria e a literatura. Um dos maiores exemplos deste tipo de escrita é a de Nathalie Quintane.

O livro em questão aqui, Les annés 10 contrariamente aos últimos livros publicados pela autora (pela P.O.L.), foi publicado por uma conhecida editora de esquerda, La Fabrique. O leitor espera uma reflexão sobre os anos 10 do nosso século XXI, uma reflexão política e também literária. Um texto que situaria esta geração no contexto histórico que lhe pertence. É o que poderíamos imaginar se o texto tivesse escrito por um professor universitário. Esse, evidentemente, não é caso de $\mathrm{Na}$ thalie.

O primeiro artigo se chama, "Stand up" e logo na primeira linha descobrimos que o assunto tratado, ou a personagem do texto em questão é Marine Le Pen, chefe do partido francês de extrema direita Front national. Não se trata de um texto crítico que apresenta as principais teses do partido para refutá-las ou explicar sua ascensão em meio a um cenário de crise. Esse talvez seja o aspecto mais interessante da natu- 
reza da crítica que se tece num texto que não é um ensaio, um texto teórico, mas um texto literário. Nathalie não se vale de sua posição para argumentar, não se serve de sua autoridade para discernir entre o certo e o errado e guiar seus leitores, ávidos de respostas para um novo futuro. Seu discurso não se confunde, de maneira nenhuma com o discurso de um partido político. Não se trata de criticar um estado de coisas, de constatar a falência da política, a ascensão monstruosa do conservadorismo mais racista e xenófobo na terra da liberdade, da igualdade e da fraternidade. Não. Esse livro não se confunde com os lamentos constantes da esquerda.

Podemos nos perguntar por que certa prosa de extrema esquerda recai na lamentação, seja ela retrospectiva ou preventiva (antecipação e reminiscência aqui se confundem, o fracasso das revoluções passadas é um traço específico da revolução - é assim que reconhecemos uma revolução: ela fracassou) (Quintane, 2014, p. 183).

Nathalie Quintane narra! Como num romance, tudo começa quando a personagem, num tempo determinado executa uma ação. Se a condessa sai de casa às cinco horas, "Nesta noite, Marine Le Pen chegou à cidade." (Quintane, 2014, p. 7) Em seguida, a narradora descreve o efeito deste evento no seu próprio corpo, para em seguida, descrever o que imagina terem sido os primeiros momentos da personagem em sua cidade:

Disseram-me: você viu, Marine Le Pen está em D. dia 29. No momento, eu apenas senti uma espécie de coma, mas nas horas seguintes, a informação, digamos, subui a cabeça, (depois de ter ocupado uma coxa, duas, um braço, a nuca, mais tesa, o pescoço todo, os dentes, a mandíbula, o nariz pelas narinas porque agora respiramos outro ar, as temporãs, a testa, os olhos, Marine Le Pen está no teto, ela se instalou, arrumou um pequeno quarto com uma cama de solteiro, um sofá, um criado mudo onde se encontra A vida de Georges Pompidou, ela mudou o lustre, muito antigo, com suas tulipas, ela colocou um neon rosa em forma de tucano na parede e degusta um twix inspecionando as unhas pintadas de seus pés) (Quintane, 2014, p. 7). 
Um humor difícil de descrever, que passa da descrição física e corporal do horror e da tensão provocados pela proximidade com a personagem, para a descrição de Marine, em seu quarto, comendo chocolate e contemplando as unhas pintadas de seus pés. Esse tom coloquial, e irônico por ser justamente familiar, onde a ironia é efeito da abundância de detalhes ou "efeitos do real" para falar como Barthes, que se forma a partir da utilização de um francês acessível - uma escrita "oral", falada (sem parecer um simples "mimetização" da fala) - coloca o leitor numa posição estranhamente confortável.

Essa é a questão que queremos abordar aqui, de que maneira o engajamento político influencia decisões de escrita e estilo. De que maneira a escrita de Nathalie é constituída por decisões de natureza política que a situam não apenas em relação aos seus contemporâneos, os escritores oficiais, (ganhadores de prêmios literários), os autores de best-seller, mas também com relação ao contexto histórico no qual o livro está inserido e que influenciará sua recepção? Este é o assunto de outro artigo deste livro: "Por que a extrema esquerda não lê literatura?"

Que o leitor não se engane, a autora está se referindo a si mesma. Ela confessa que prefere ler estudos sociológicos, ensaios e crítica literária, e que lê muito pouca literatura. Ora, um livro de crítica literária pode ser tão agradável quanto a literatura. Agradável significa que o livro contém algo de estranho, um "pequeno mistério" no interior de um todo que é perfeitamente reconhecível, familiar. É isso o que procuramos na literatura.

Mas em que língua são escritos estes livros agradáveis? Há a língua escolar, fluída poderíamos dizer, porque correta. Há também o francês de qualidade, a boa língua. Esta língua clássica pode ser tão danosa para os acontecimentos descritos quanto a língua "da moda", ambas tornam o que narram datado. Podemos sonhar com um francês límpido que clarificaria o real, o tumulto, a bagunça, ou que poderíamos contaminar a bagunça com uma língua clara, transformando-a. Escrever é uma “operação mágica”. Mas qual a sua natureza?

Nathalie discute duas teses famosas do estruturalismo. A primeira consiste em afirmar a inutilidade ou a utilidade particular e especial que concerne os textos literários. A segunda, a necessidade de pensar a linguagem própria à literatura, distinguindo-a dos usos ordinários e jornalísticos, no interior da comunicação. 
Diante do fato de que hoje, ninguém se preocupa em emitir uma opinião sobre a literatura, e esta está confinada a um círculo restrito de amadores e especialistas, afirmar que esta é inútil só contribui para aumentar seu isolamento. (“C'est qu'aujourd'hui, déclarer que la littérature est inutile, c'est participer à sa mise en bière ». (Quintane, 2014, p. 187) A literatura concerne hoje seus leitores quando estes encontram sua experiência retratada. $O$ debate sobre a literatura se reduz a questões judiciais, caso de polícia e magistrados. Tudo se resolve num tribunal. Ela produz processos. A questão é: “isto é ou não é literatura?" E na maioria das vezes a resposta é "institucional", trata-se de literatura quando o autor é reconhecido como um escritor. Nestas condições a literatura é social quando produz "efeitos do real" que alguns confundem com efeitos sociais. Se a literatura produz realmente e verdadeiramente efeitos sociais, então já não estamos mais tratando de literatura, porque esta só produz o que é literário. Ou seja, um escritor é reconhecido como tal, quando os efeitos sociais de seu trabalho são nulos. Mas quem quer ser condenado à inocência? Assim, para não passaram despercebidos, os escritores procuram a mídia. Diante desta situação, Nathalie não hesita em afirmar que o que há de autenticamente literário na ação do escritor, não é o desejo de produzir efeitos de realidade, mas o desejo de fazer, de produzir, realmente, verdade, numa sociedade cada vez mais higienista no que diz respeito à literatura. (Quintane, 2014, p. 191)

E como se faz esta literatura que deseja produzir mais que efeitos realidade, e sim verdade?

Nathalie não critica os "efeitos de real" da literatura porque se coloca terminantemente contra todo tipo de "realismo". A questão, dada a situação da literatura nas nossas sociedades, é muito mais delicada. Por um lado, para que a literatura possa se redimir do "pecado moderno" que a coloca como meio e fim em si mesmo, e se libertar da maldição pós-moderna no interior da qual tudo é texto, e em que se abandona a busca por um "impossível do real" ou do "real impossível" é preciso que ela demonstre uma posição ética com relação às coisas, uma atenção que não acrescenta, nem na língua nem nos fatos. Uma escrita desprovida de afetos, mas também de adornos. Esta "literatura de constato" barra as leituras projetivas e a dimensão projetiva do ato literário. No entanto, se tememos a literatura de vanguarda, estamos fadados a uma escrita que "descreve a ordem social existente como a única ordem conhecida e conhecível, e esta ordem de fato é no fundo a única crível, 
aquela na qual devemos acreditar em todo caso pelo menos durante a leitura, porque esta depende da crença na narrativa." (Quintane, 2014, p. 193) A impossibilidade de questionar ou duvidar da escrita literária contamina a possibilidade de colocar em questão a ordem social. 0 realismo levado às últimas consequências pode nos tornar conscientes do que está errado, e dos problemas que enfrentamos, mas nos impede de pensar como seria se tudo fosse diferente, não somos capazes de pensar que "poderia ser diferente". Ou seja, sem colocar em questão a forma da literatura não é possível questionar a ordem social.

Infelizmente esta não é a opinião que se costuma ter sobre a relação entre literatura e política. Nada mais incerto, hoje, do que o caráter político da literatura, nada mais questionável hoje do que a natureza eminentemente política da criação literária. A autora afirma que, para ela, o contexto no qual um livro se insere, com relação à situação atual ou passada e também aos outros autores contemporâneos, seria mais importante politicamente do que o retorno em massa da "referência". Ela acreditava que escrever Chassure seria suficiente, mas compreendeu em seguida, com a publicação de Tomates que a tematização se tornara indispensável: "o livro para ser político, deve falar sobre política. Se para ser político, devemos falar de política, então é porque não compreendemos mais o que é político (nem mesmo a política)" (Quintane, 2014, p. 197). Mas, não é possível que para ser político o escritor deva fazer um trabalho de polícia ou judicial, comparável ao do Estado. Não é possível que para escrever sobre ditadura seja preciso apresentar ao leitor um ditador ou que para escrever sobre dominação seja preciso apresentar dominados com suas identidades, nome, telefone, endereço e descrever seus rostos e mãos.

Neste momento, em que a História parece ter sido esquecida, é preciso resgatar os espaços de memória, e a "perspectiva" que a História oferece: uma alternativa que nos desviaria de uma realidade a qual parecemos irremediavelmente condenados. Nathalie não conclui com uma lamentação, mas salientando que hoje cresce a consciência da necessidade de se falar em nome da verdade, e por essa razão já desponta, no que foi dito aqui, e podemos acrescentar, em outros textos da mesma autora, um recomeço.

Só podemos esperar, e a escrita de Nathalie, confirma esta hipótese, que este seja mesmo só o começo de uma renovação da literatura. 0 começo de uma literatura política, engajada que não teme dizer 
a verdade e falar em nome da verdade, mas também e, sobretudo de uma literatura que tenha a coragem de renovar suas formas e que reencontrará seu poder político ao alargar e dissolver os limites do real com imaginação, experimentação, para se tornar o que é: um convite à descoberta e à invenção.

E o que dizer da crítica literária diante deste recomeço da literatura? Ler é descobrir num livro algo de novo, inusitado, inesperado que desconcerta e encanta. o que desconcerta numa escrita, quando ela é nova, é a falência dos modos através dos quais a crítica pensa a literatura, o que encanta é que o exercício crítico é movido pelo mesmo desejo que a literatura, o desejo da descoberta. o que encanta na descoberta de uma escrita nova é a graça e leveza das ideias fresquinhas, que fornecem a certeza de que toda aposta na literatura é a confirmação de que a lamentação está com os dias contados. Os melancólicos, os desencantados, os nostálgicos se cansarão, a literatura não. Diante da coragem e da imaginação do escritor, da decisão de escrever que inventa, cria e abre novos caminhos a crítica literária também recomeça. Ler já não é mais suficiente, é preciso escrever para partilhar a alegria da descoberta. Crítica literária e literatura são assim um mesmo exercício de reflexão e invenção: uma busca por outras formas de dizer ou exibir o que é da ordem da verdade. 